\title{
The Impact of Self-Esteem on the Attitudes Towards Homosexuality
}

\author{
Prof.As.Dr. Fatbardha Osmanaga
}

Department of Psychology and Social Work. University "Luigj Gurakuqi” of Shkodër Faculty of Education. Albania.

\section{Abstract}

Diversity is part of our everyday lives. It is present everywhere, so it is present in health care settings also. The medical staff serves all the patients, regardless their gender, their race, their religion, regardless their economic status, sexual orientation, political beliefs, etc. It is very important for the medical staff to accept and respect the diversity. In this way, the quality of offered services will be the same for all the people. Having good attitudes towards homosexual individuals is one of the ways of accepting and respecting human diversity. One of the sources of good attitudes towards homosexuality is the having good self-esteem. The paper aims to analyze the impact of self-esteem on the attitudes toward homosexuality of heterosexual students of Professional Master in Nursing, branch of the Faculty of Natural Sciences. It is used the technique of questionnaire. The measuring instruments are: a)Self-Esteem Scale (Rosenberg, 1965), b)Attitudes Toward Sexual Orientation: An Adaption of Herek's ATLG Survey (the adaption is made by Benjamin J. Stefonik). The data collected from the questionnaire was analyzed by means of the SPSS program, variant 20. In the study, we had the participation of 77 heterosexual students of Professional Master in Nursing, 40 students frequent the first academic course and 37 students are at the second academic course. The paper concluded that there is positive correlation between heterosexual students' self-esteem and their attitudes towards homosexuality (Sig. $=0.083$ ). Their selfesteem is not too positive and their attitudes towards homosexuality are not good. The students prejudice the homosexual individuals. It is very important the improvement of self-esteem and the improvement of the attitudes toward homosexuality of heterosexual students of Professional Master in Nursing, branch of the Faculty of Natural Sciences. The improvement of their self-esteem and their attitudes toward homosexuality will influence the quality of their work. There are defined the main strategies in order to improve students' self-esteem and their attitudes toward homosexuality.

Keywords: Self-esteem, attitudes, homosexuality.

\section{Introduction}

Nursing philosophy is based on humans and caring. Humans are unique and have a need to be understood. Nursing is described as a 'helping discipline', with a focus on interaction between the nurse and the patient, and relies on communication, participation and the nurse understanding both herself/himself and others (Bentling 1995; McCabe 2004). Working as a nurse builds on the nurse having a positive attitude to all patients and understanding the patient's needs as well as understanding that her/his own values influence her/his actions and behavior (Rőndahl, G.2005).

Attitudes of health professionals can influence the willingness to provide help to homosexual patients (Yen et al. 2007) and consequently the quality of health care and treatment. Furthermore, medical students' attitudes towards homosexuals are of great importance as the young are more prone to change and could be better promoters of anti-stigma programs. In addition, anti-stigma programs could help in spreading non-homophobic attitudes towards clients and patients, as well as in raising the awareness on how the attitudes of physicians and medical staff lead to negative social, ethical, and 
psychological consequences. (Dunjić-Kostić B., Pantović M., Vuković V., Randjelović D., Totić-Poznanović S., Damjanović A., Jašović-Gašić M., Ivković M., 2012).

Weinberg"s theory states that individuals who are able to overcome their homophobia would have improved feelings about themselves (as cited in Wells, 1991). Morin (1974) also found that the students who had more positive self-concepts had significantly less homophobia (as cited in Wells, 1991) (cited by Miller S.N.)

Investigators such as D'Augelli and Rose (1990), Engstrom and Sedlacek (1997), Hensley (1995), Kite (1984), Nelson and Krieger (1997), Reinhardt (1997), Rey and Gibson (1997), Simoni (1996), Waldo (1998), and Whitney (2002) have linked a variety of personal traits to feelings of homophobia. Gender-roles and gender, self-esteem, education level, race/ethnicity, religiosity, geographical area of residence, political preference, income level, and exposure to homosexuals can influence people's feelings about homosexuals. Overall, women are more accepting of homosexuality than men, as are people who have high self-esteem; a higher level of education; higher income; more exposure to homosexuals; who are less active in organized religion; who identify as being politically moderate or liberal; who are not of an ethnic minority; and who live in less conservative areas of the country and/or in more urban settings (Smith M.S., 2004).

\section{Methodology of the paper}

As it was mentioned above, people's self-esteem impacts their attitudes towards homosexuality. It is considered necessary the measurement of nurses' attitudes towards homosexuality, because they serve homosexual people at their work. It is, also, necessary knowing their level of self-esteem, in order to create an idea about one of the sources of their attitudes towards homosexuality. A great part of the nurses of the city of Shkoder are students at Professional Master study programme. So, it was designed this research. There are conducted a lot of similar studies at the world. For example:

Gerd Rőndahl made a similar study on 2005 at one infectious disease clinic in central Sweden. 48 nurses, 37 assistant nurses, 113 nursing students, 165 assistant nursing students participated in the study. In general, the participating nursing staff and students expressed positive attitudes, though some subjects reported very negative attitudes towards gay people (Rőndahl, G.2005).

The study made by Samantha J. Boch at Ohio State University, College of Nursing on 2011, at a college of nursing in a large Midwestern university. The sample consisted of 369 participants: 36 faculty members and 333 nursing students. Overall, the results show that homophobia exists in this Midwestern college of nursing (Boch S.J., 2011).

The results of the study (in 2009) made with the participation of the students at the School of Medicine, University of Belgrade, and the physicians employed at the Clinical Center of Serbia, were that male participants showed a lower level of knowledge about homosexuality and a higher tendency to stigmatize homosexually oriented individuals (Dunjić -Kostić B., Pantović M., Vuković V., Randjelović D., Totić-Poznanović S., Damjanović A., Jašović-Gašić M., Ivković M., 2012).

Aims and objectives of the paper. The main aim of the paper is analyzing the impact of self-esteem of heterosexual students of Professional Master in Nursing, branch of the Faculty of Natural Sciences, on their attitudes toward homosexuality.

The objectives of the paper are:

Measuring self-esteem of heterosexual students of Professional Master in Nursing, branch of the Faculty of Natural Sciences.

Measuring attitudes toward homosexuality of heterosexual students of Professional Master in Nursing, branch of the Faculty of Natural Sciences.

The research question is: What is the relationship between self-esteem of heterosexual students of Professional Master in Nursing and their attitudes towards homosexuality? 
Sampling. In the study, we had the participation of 77 students of students of Professional Master in Nursing, branch of the Faculty of Natural Sciences. The students claimed that are heterosexual. 5 questionnaires were considered as invalid, because there it was not given the sexual orientation of the students that fulfilled these questionnaires. 40 students $(51,9 \%$ of students participating in the study) frequent the first academic course and 37 students $(48,1 \%)$ are at the second academic course. 74 students (96,1\% of students participating in the study) are female, 3 students $(3,9 \%)$ are male. In the study we had the participation of students of different ages. Their age varies from 21 years aged (1 student) to 39 years aged ( 1 student). The mean is 25,05 years. 54 students $(70,1 \%$ of students participating in the study) work as nurse, whereas 23 students $(29,9 \%$ of students participating in the study) don't work as nurse. 18 students $(23,4 \%$ of students participating in the study) recognize homosexual individuals, 58 students $(75,3 \%)$ do not recognize any homosexual individual, whereas 1 student (1,3\% of students participating in the study) has not given any answer.

Apparatus/Materials. It is used the technique of questionnaire. The measuring instruments are: a)"Self-Esteem Scale" (Rosenberg, 1965) to measure students' self-esteem.

The scale is a ten item Likert scale with items answered on a four point scale - from strongly agree to strongly disagree (cited by the link: http://www.yorku.ca/rokada/psyctest/rosenbrg.pdf).

Scoring: Items 2, 5, 6, 8, 9 are reverse scored. Give "Strongly Disagree" 1 point, "Disagree" 2 points, "Agree" 3 points, and "Strongly Agree" 4 points. Sum scores for all ten items. Higher scores indicate higher self-esteem (cited by the link: http://fetzer.org/sites/default/files/images/stories/pdf/selfmeasures/Self_Measures_for_Self-

\section{Esteem ROSENBERG SELF-ESTEEM.pdf).}

b)"Attitudes Toward Sexual Orientation: An Adaption of Herek's ATLG Survey "(the adaption is made by Benjamin J. Stefonik). The questionnaire consists of 20 -items and is presented in Likert format with a 5 -point scale ranging from "strongly disagree" to "strongly agree" (Herek, 1984). The range of possible aggregate scores is 20 points (least prejudice attitudes toward homosexuals) to 100 points (most prejudice attitudes toward homosexuals) (cited by the link: http://www.foothill.edu/attach/1474/10 PaperExemplar.pdf).

The questionnaires have been filled out by the students themselves. The administration of the questionnaires and the interviews (distribution and collection) was conducted during November-December 2016.

Method of analysis. The data collected from the questionnaire was analyzed by means of the SPSS program, variant 20. It is estimated the reliability of the questionnaire. The internal reliability, Alpha Cronbach coefficient $=0,89$.

Piloting stage. It is realized the piloting phase for both the questionnaires at previous studies made by the author. The internal reliability of the Self-esteem Scale was $=0,797$ (Osmanaga F., 2014). The internal reliability of the questionnaire "Attitudes Toward Sexual Orientation: An Adaption of Herek's ATLG Survey" Alpha Cronbach = 0,92 (Osmanaga F., 2015). It is calculated Alpha Cronbach now and it is concluded that Alpha Cronbach for the Self-esteem Scale is 0,83 and Alpha Cronbach of the questionnaire "Attitudes Toward Sexual Orientation: An Adaption of Herek's ATLG Survey" is 0,88.

\section{Findings of the study:}

\section{General data concerning students' self-esteem}

Table 1. Data about students 'self-esteem

\begin{tabular}{|l|l|l|l|l|l|l|l|}
\hline & N & Mean & Median & Mode & $\begin{array}{l}\text { Standard } \\
\text { Deviation }\end{array}$ & Minimum & Maximum \\
\hline Self-esteem & 77 & 19,89 & 19 & 18 & 3,37 & 14 & 28 \\
\hline Valid & 77 & & & & & & \\
\hline
\end{tabular}


The mean is 19.89 , the median is 19 and the mode is 18 . The maximum score obtained is 28 (obtained from 1 student or $1.3 \%$ of students), the minimum score obtained is 14 (obtained from 2 student or $2.6 \%$ of students). It is given the corresponding histogram (the graph 1).

Graph 1. Data about students'self-esteem

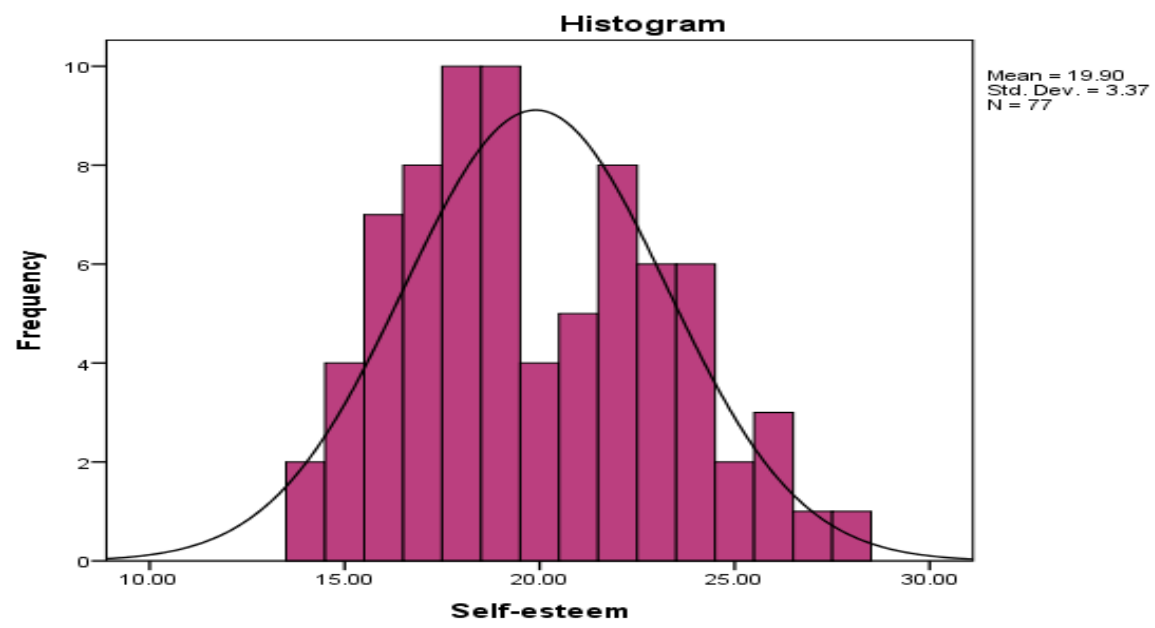

A considerable fraction of the values obtained is ranked in the range of values from 14 to 20 (45 students or $58.44 \%$ ). In the range of values from 21 to 25 is ranked another portion of the results (27 students or $35.06 \%$ ). A small fraction of the values obtained is ranked in the range of values from 26 to 28 (5 students or $6.49 \%$ ). So, we can say that students' selfesteem is not too positive.

\section{General data concerning students' attitudes toward homosexuality}

Table 2. Data about students' attitudes toward homosexuality

\begin{tabular}{|l|l|l|l|l|l|l|l|}
\hline & N & Mean & Median & Mode & $\begin{array}{l}\text { Standard } \\
\text { Deviation }\end{array}$ & Minimum & Maximum \\
\hline Attitudes & 77 & 59,64 & 59 & 58 & 8,56 & 38 & 82 \\
\hline Valid & 77 & & & & & & \\
\hline
\end{tabular}

The mean is 59,64 , the median is 59 and the mode is 58 . The maximum score obtained is 84 (obtained from 1 student or $1,3 \%$ of students), the minimum score obtained is 38 (obtained from 1 student or $1,3 \%$ of students). It is given the corresponding histogram (the graph 2). 
Graph 2. Data about students' attitudes towards homosexuality

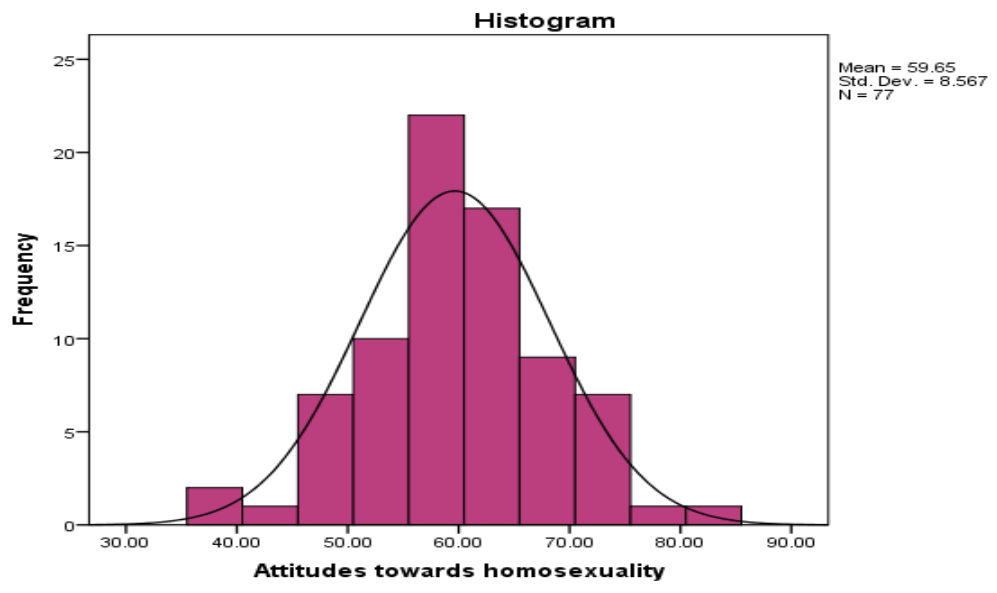

A small fraction of the values obtained is ranked in the range of values from 38 to 50 (10 students or $12,99 \%)$. The most of the results obtained is ranked in the range of values from 51 to 60 (32 students or $41,56 \%$ ). A considerable fraction of the values obtained is ranked in the range of values from $61-70$ (26 students or $33,77 \%$ of the students participating in the study). A small fraction of the values obtained is, also, ranked in the range of values from 71 to 82 ( 9 students or 11,68\%). So, we can say that there exist prejudice attitudes toward homosexuality.

\section{The relationship between heterosexual students' self-esteem and their attitudes towards homosexuality}

There is positive correlation (but no strong relation) between heterosexual students' self-esteem and their attitudes towards homosexuality (Sig. $=0.083$ ). Their self-esteem is not too positive and their attitudes towards homosexuality are not good. The students prejudice the homosexual individuals.

\section{Conclusions}

There is positive correlation between heterosexual students' self-esteem and their attitudes towards homosexuality. Their self-esteem is not too positive and their attitudes towards homosexuality are not good.

\section{Recommendations}

It is very important the improvement of self-esteem of students of Professional Master in Nursing, branch of the Faculty of Natural Sciences. It is very important, also, that the students have good attitudes toward homosexuality. So, it is very important the improvement of their attitudes toward homosexuality. The improvement of their self-esteem will influence the quality of their work. So, improving students' self-esteem will result in improving the quality of services for people. Other studies should be made in order to detect the causes of their low self-esteem.

According to the social contact theory, exposure to information about homosexuality or actually meeting a homosexual individual can positively affect an individual's attitude toward homosexuals (Lance, 1994). Direct contact with a homosexual is believed to dispel myths, reduce fear, promote mutual understanding and reduce prejudice toward homosexual individuals (cited by: http://www.foothill.edu/attach/1474/10_PaperExemplar.pdf, pg.4). 
An effective strategy for improving students attitudes toward homosexuality will be the organization of different meetings with homosexual individuals or the organization of various meetings with the representatives of their organizations. The Faculty should try to organize such meetings, for example, workshops, open lectures with the focus about sexual orientation.

It is very important the involvement in different academic subjects of a lot of topics that address homosexuality. So, the students will have more knowledge about homosexuality and this will improve their attitudes towards homosexuality.

There are needed further studies in order to find out other sources of prejudices toward homosexual individuals.

\section{References}

[1] Dunjić -Kostić B., Pantović M., Vuković V., Randjelović D., Totić-Poznanović S., Damjanović A., Jašović-Gašić M., Ivković M. (2012). Knowledge: a possible tool in shaping medical professionals'attitudes towards homosexuality. Psychiatria Danubina, 2012; Vol. 24, No. 2, pp 143-151. Medicinska naklada - Zagreb, Croatia, fq. 143

[2] Osmanaga F. (2014). Students'perceptions about self-esteem. Journal of Educational and Social Research", ISSN 2239-978X(Print) ISSN 2240-0524(Online).

[3] Osmanaga F. (2015). "Student's attitudes toward homosexuality. European Scientific Journal, ESJ's 2015 August edition).

[4] Rőndahl, G.2005. Heteronormativity in a Nursing Context. Attitudes toward Homosexuality and Experiences of Lesbians and Gay Men. Acta Universitatis Upsaliensis. Digital Comprehensive Summaries of Uppsala Dissertations from the Faculty of Social Sciences 1.62 pp. Uppsala. ISBN 91-554-6199-9.

[5] Smith M.S. (2004) "Attitudes of Resident Assistants Toward Homosexuality and Gay and Lesbian Students: A Study at a Southeastern Research University". Master's Thesis, University of Tennessee, pg.2

\section{Links}

http://www.foothill.edu/attach/1474/10_PaperExemplar.pdf

http://www.hdbp.org/psychiatria_danubina/pdf/dnb_vol24_no2/dnb_vol24_no2_143.pdf

http://www.lycoming.edu/library/archives/documents/SaraMillerpaper.pdf, fq.8

http://www.mcser.org/journal/index.php/jesr/article/view/4176

http://www.yorku.ca/rokada/psyctest/rosenbrg.pdf).

http://eujournal.org/index.php/esj/issue/view/196

http://fetzer.org/sites/default/files/images/stories/pdf/selfmeasures/Self_Measures_for_Self-

Esteem_ROSENBERG_SELF-ESTEEM.pdf).

http://kb.osu.edu/dspace/bitstream/handle/1811/51928/ThesisSamanthaJBoch.pdf

https://uu.diva-portal.org/smash/get/diva2:166121/FULLTEXT01, fq.19 